\title{
Study on the Mode of Inheritance and Innovation of Industrial Buildings in Suzhou
}

\section{Gu Xingkai}

Suzhou Art and Design Technology Institute, Suzhou, China

\begin{abstract}
Keywords: Industrial Building; Building Inheritance and Innovation; Sustainable Development
\end{abstract}

\begin{abstract}
With the development of the city and the upgrading of the industrial structure, a large number of industrial buildings are left idle due to the loss of productive functions or abandonment. In the past, the Chinese government simply took all demolition and reconstruction measures to deal with such buildings, resulting in waste of resources and environmental pollution, which is also helpless to inherit the urban context and solve social problems. In the western developed countries, the transformation and reuse of old industrial buildings have entered into a fairly mature stage, while China is lagged behind because of many factors such as late start time, humanity, historical context breaking and no-standardized policy guidelines. Based on the analysis of the relevant development process both at home and abroad, this paper summarizes the advantages, constraints, general principles and design methods of transformation and re-use of industrial buildings. In the light of the reform and reutilization of a large number of old industrial buildings in the process of urban renewal in China, a typical case of the transformation and reuse of the old industrial building in Suzhou industrial park is analyzed, to provide the pertinent suggestions and measures for inheritance and innovation of China's industrial buildings.
\end{abstract}

\section{Introduction}

With the acceleration of the process of urbanization, the city is an organism that is constantly expanding. The scale of the city has continued to expand outward both in space and in capacity. The earliest planned industrial enterprises in the periphery or periphery of cities started to move away from their sites [1]. On the other hand, With the improvement of social productive forces, accelerated economic development, the transformation of the traditional industrial structure, the rise of new industries, the upgrading of industrial structure and the improvement of industrial quality and production efficiency, this has directly led to the gradual decline of old industrial areas, Leaving a large number of old industrial buildings are idle [2].

The life span of a typical building refers to both the service life and the service life. When the functional life of a building is completed within a certain historical period, its service life can often be continued. Guided by the concept of sustainable development [3], the process of rebuilding and reusing old industrial buildings is essentially a process of secondary development and design of old buildings that still have a useful life and give them new functional life. In this way, not only can we reduce the demolition of old buildings, save construction materials, but also to a certain extent, inherit the historical context of the city. The developed countries in the West have come to our forefront in this regard and have accumulated relevant experience through certain practical experiences [4]. China's reform and reuse of old industrial buildings started in the 1980s. Most of them were formed spontaneously by social pioneers and groups of non-governmental organizations. They lacks systematic norms of operation. Mostly, they stay at the sensory level such as appearance modification and interior decoration, and only a single analysis of specific cases, no relevant experience and methods of summary, combing, in the old industrial building renovation and reuse of the relevant factors, the transformation of superiority, re-use strategies failed to further study[5].

The transformation and reuse of old buildings mean that under the guidance of the theory of sustainable development, the process of redesigning the buildings that have lost their original functions and using them after changing their functions is not simply to repair or adjust them [6]. 
Instead, In the premise of meeting the requirements of new functions, the quality of buildings at the same time to enhance the project. According to the definition of "Encyclopedia of Architecture, Design, Engineering and Construction", "Re-use" refers to "creating a new usage function in the field of architecture or reconfiguring a building to adapt to a new space form, which can continue to extend the life of the building [9]. Reuse of the building so that we can capture the value of the building in the past, make full use of it, and turn it into a new vitality of the future. "The most essential purpose of the transformation and reuse of old buildings is to make" Old "buildings and" new "functions and environment" symbiosis. Therefore, we can understand that the original function of a building should be changed so as to adapt to the basic spirit of building reutilization when it is needed in the future or in the meantime, in order to adapt the original building to the new functional requirements, make some appropriate modifications to it and introduce modern equipment [10]. Whether it is to be preserved or dismantled as it is, the superficial treatment is a more sensible move to find new vitality for the old buildings.

This paper summarizes the development process of reconstruction and reuse of old industrial buildings both at home and abroad, cuts the theme from the advantages and constraints of transformation and reuse, analyzes the concrete and feasible reform strategies, and combines with a relatively The typical old industrial plant transformation and reuse of the actual case, analysis of the status quo problems and deficiencies, hoping to sort out some of the recommendations for the reform and re-use, for future practical activities to provide a reference.

\section{Typical characteristics of old industrial buildings inheritance in Suzhou}

The old industrial buildings have different types and characteristics according to their original functions. Generally speaking, classification according to the way of rebuilding and reusing old industrial buildings can be divided into three categories: reconstruction, expansion and comprehensive rebuilding. According to the characteristics and scale of old industrial buildings, they can be classified into single-story factory buildings, multi-story factory buildings, space industrial structures (such as storage rooms, cooling towers, etc.), this paper mainly from the classification of its spatial characteristics and scale description.

\subsection{Single-story Plant Rebuilding}

Generally, the single-story plant refers to the single-story and long-span industrial plant, of which the support structure are mostly giant steel frame with large-span, high-level high-rise, structural fastness, and strong plasticity. Such old industrial buildings can continue to give full play to their original characteristics of open space and are usually transformed into shopping malls, exhibition halls, theaters, art galleries. In Suzhou Industrial Park, the design method of "zeroing out" is adopted to change the internal space organization in all directions according to different functions of such buildings, thus forming a rich and varied spatial combination as shown in Fig.1.

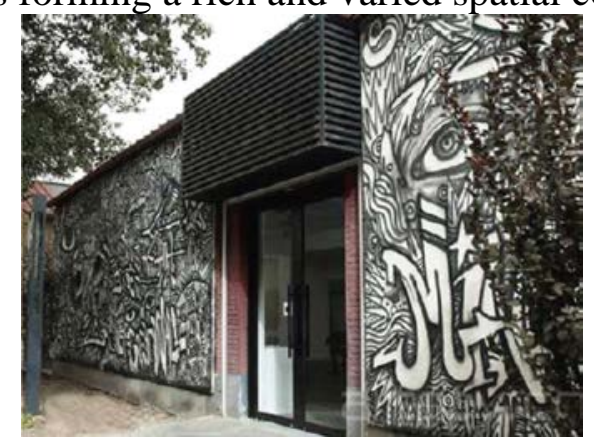

Fig.1 Single-story plant rebuilding in Suzhou

\subsection{Multi-story Plant Rebuilding}

The multi-story plant mostly have the framework structure, which are commonly used in light industrial multi-story plant and warehouse. Such buildings with small span and low-level features 
are mostly equipped with the framework of structural systems, which are also easy to create a better urban space.

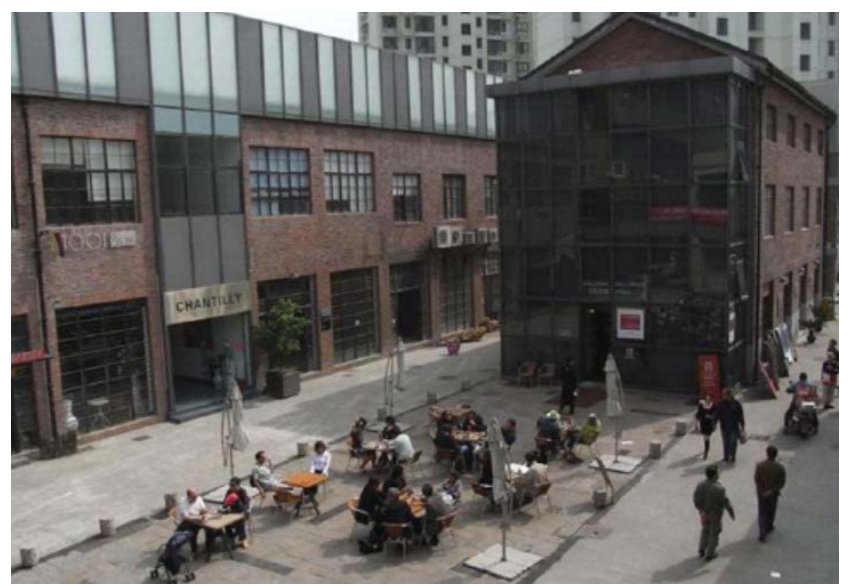

Fig.2 Multi-story plant rebuilding in Suzhou

In Suzhou Industrial Park, such old industrial buildings can play the advantages of large space flexibility, and these features of the building height and space requirements are relatively small, according to the column network layout in horizontal space based on the use of different functions of the flexible division of space. In the vertical direction, it can also increase or decrease the floor by local methods to create atrium space or enrich the space level. In addition, the facades and roofs of this type of building have a great deal of flexibility to create alternative architectural forms. The multi-story plant rebuilding in Suzhou is presented in Fig.2.

\subsection{Shaped Space Rebuilding}

Shaped Space mainly refers to some industrial structures with special spatial forms such as cooling towers and chimneys due to their special use functions. Shaped space of such buildings has brought great constraints and obstacles to the reconstruction work, but from another perspective, it also provides rich imagination for the reconstruction and reuse of old buildings. In Suzhou Industrial Park, such buildings are suitable for transformation into different sizes of buildings such as park sketch an urban sculpture, but also its unique shape and the existing urban landmark together for the development of the city's tourist attractions as shown in Fig.3.

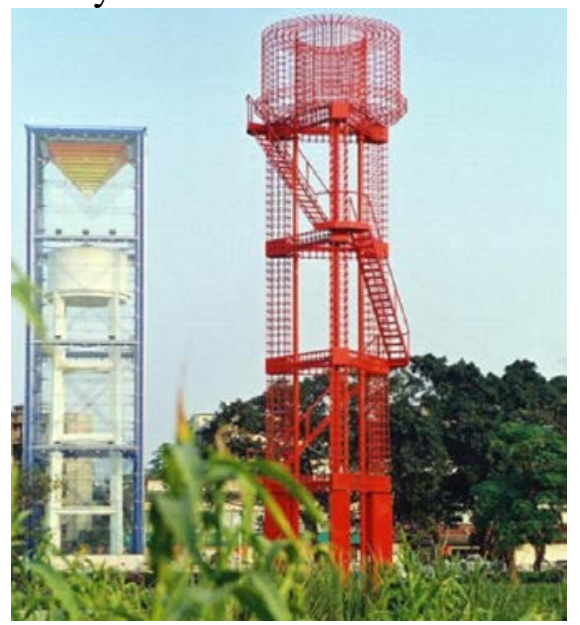

Fig.3 Shaped space rebuilding in Suzhou

\section{Typical Case Study on Innovation of Old Industrial Buildings in Suzhou Industrial Park}

Located in the southeast of Jiangsu Province and the eastern part of Suzhou City, Suzhou Industrial Park covers an area of 27.8 square kilometers and was approved by the State Council in February 1994. It is a cooperation project of the two governments of China and Singapore, and initiated the mutually beneficial cooperation between China and foreign countries in economic and 
technological fields New form By 2006, the development of the park has begun to enter a crucial period of industrialization transformation, urbanization and internationalization. In 2001, on the occasion of the 20th anniversary of the establishment of the park, in order to thoroughly implement the spirit of the 18th CPC National Congress, In response to the requirements of the modernization demonstration zone in southern Jiangsu Province, Suzhou Industrial Park leads the modernization development and takes the transformation of development mode as a way to enhance the park's energy level, promote the construction of ecological civilization and guide the construction of the park into an internationalized, modernized and informatized Science and technology park and innovative, eco-friendly, happy integrated business district. The use of old industrial buildings after re-use has become a re-use of the park "retreat into three" concept of sustainable development in one of the specific practices. This article focuses on the Pingjiang Street, No. 1 plant transformation and reuse is one of the more representative of a case.

\subsection{Create multiple natural spaces}

The old industrial buildings are the products of industrialization. They tend to have large building area and interior space on the basis of meeting the requirements of the production process. They are large in span, deep in depth and relatively easy to separate, easy to form a simple space for use, and the external envelope is relatively Tough and open is not strong. Throughout the renovation process, the original large open space was re-partitioned and integrated according to the new usage function. In addition to the main office space, the interior design of the courtyard, the green lounge space and the outdoor Open landscape and other multi-level natural space.

\subsection{The first natural space - open courtyard interior}

During the renovation process, large-scale lighting windows were opened on the façade wall and two "Z" -shaped open courtyards were set up in the center of the original building with an area of about 320 square meters and were formed by planting green plants of different specifications Rich landscape of greenery, combined with the setting of water bodies and landscapes to form an open space. Meanwhile, it also solves the problem of ventilation and poor lighting conditions in the interior rooms. It can serve both purposes and forms the first natural space in Figure.4.

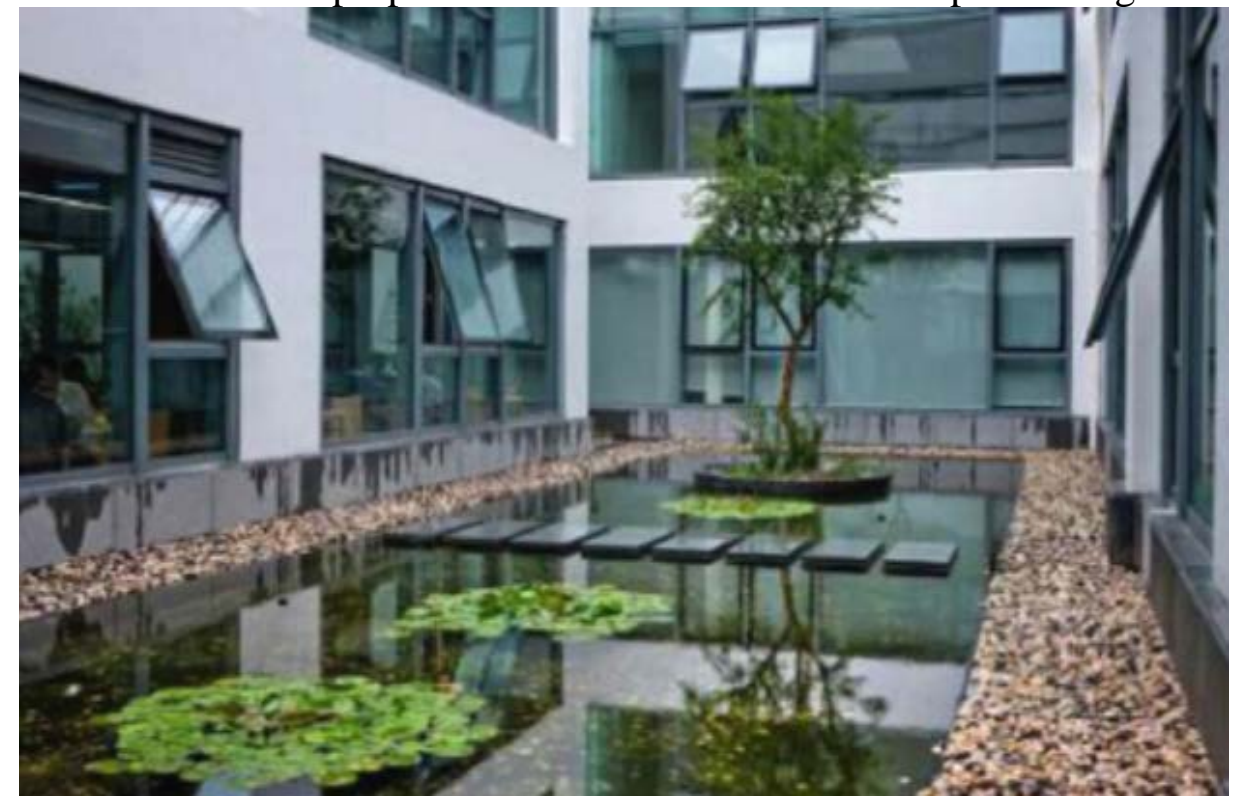

Fig.4 The first natural space - open courtyard interior

\subsection{The second largest natural space gallery}

The second is the natural space in the original plant on the basis of the external structure of an increase of 2.4 meters wide, forming a semi-open outdoor space, and corridor for the use of green plants use the sun effect, the formation of ecological shade, the use of wood Bucket green, planting ornamental strong flowers, so that the second part of the natural space to meet the evacuation 
function under the premise of the formation of indoor and outdoor gray transitional space, creating a beautiful natural scenery, a place to rest and exchange (see Figure.5).

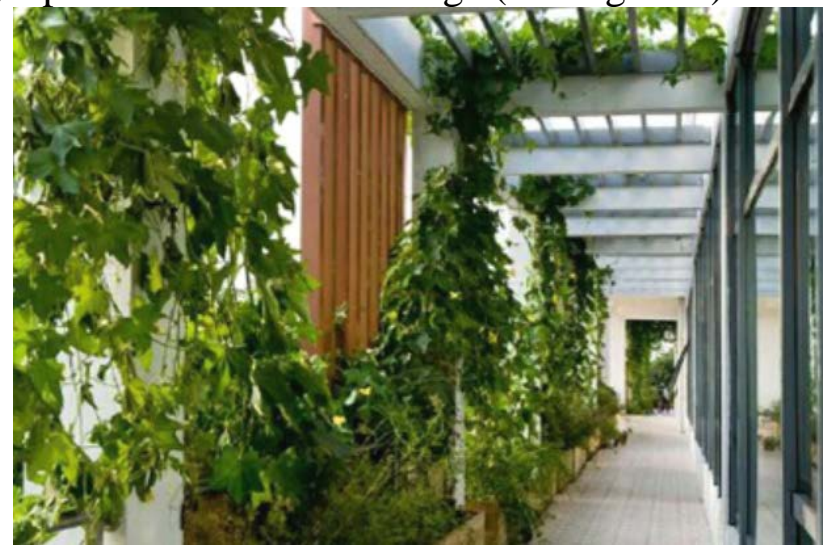

Fig.5 The second largest natural space gallery

\subsection{The third natural space - outdoor patio space}

The third one is the outdoor courtyard space which is open to the outside world. In combination with other natural environments within the project, the project will create an old industrial transformation and reuse building with beautiful environment, rich space and harmonious coexistence between man and nature, which is presented in Fig.6.

After the transformation of the triple natural space in the physical function to solve the ventilation, lighting, drainage problems, and in the original 14-meter-high local space, layout for the staff to exercise leisure gym and badminton court, and more to meet people's physical and mental requirements. The function of the original buildings limits the range of human activities, resulting in a single function of space and incompatible with nature and man. After the transformation, through the transition and coordination of the triple natural space, people's activities are cleverly integrated with the natural environment. Together, the function of space becomes enriched, and human activity enhances the vitality of the building and enhances the usability of the site, enhancing the level and place of space.

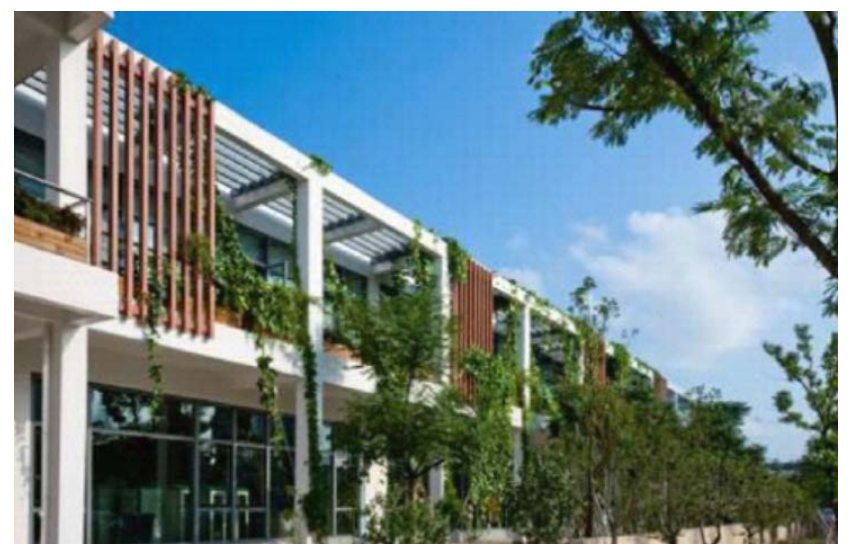

Fig.6 The third natural space - outdoor patio space

\section{Conclusions}

In this study, the mode of inheritance and innovation of industrial buildings in Suzhou Industrial Park is analyzed in detail, to provide the pertinent suggestions and measures for inheritance and innovation of China's industrial buildings. Typical characteristics of old industrial buildings inheritance in Suzhou are presented at first, where three categories of old industrial buildings including single-story, multi-story and space industrial structures are presented to interpret the basic inheritance and innovation method of industrial buildings in Suzhou. Then, the typical case of old industrial buildings in Suzhou Industrial Park is provided, of which the multiple natural spaces is 
the representative of inheritance and innovation of industrial buildings in Suzhou. Based on the previous analysis, the innovative industrial building rebuilding method with Suzhou label is presented, which can provide reference for future old industrial building inheritance and rebuilding.

\section{References}

[1] Gokhberg L, Roud V. Structural changes in the national innovation system: longitudinal study of innovation modes in the Russian industry [J]. Economic Change and Restructuring, 2016, 49(23): 269-288.

[2] Berry H. Knowledge inheritance in global industries: The impact of parent firm knowledge on the performance of foreign subsidiaries [J]. Academy of Management Journal, 2015, 58(5): 14381458.

[3] Heitz A, Beziat A. The parcel industry in the spatial organization of logistics activities in the Paris Region: inherited spatial patterns and innovations in urban logistics systems [J]. Transportation Research Procedia, 2016, 12: 812-824.

[4] Adams P, Fontana R, Malerba F. User-industry spinouts: Downstream industry knowledge as a source of new firm entry and survival [J]. Organization Science, 2015, 27(1): 18-35.

[5] Gibson C. Material inheritances: how place, materiality, and labor process underpin the pathdependent evolution of contemporary craft production [J]. Economic Geography, 2016, 92(1): 6186.

[6] Miörner J, Trippl M. Paving the way for new regional industrial paths: actors and modes of change in Scania’s games industry [J]. European Planning Studies, 2017, 25(3): 481-497.

[7] Zhang M Y. Innovation management in China [M]//The Oxford Handbook of Innovation Management. Oxford University Press Oxford, UK, 2014: 355-374.

[8] Savoia M, Stefanovic M, Fragassa C. MERGING TECHNICAL COMPETENCES AND HUMAN RESOURCES WITH THE AIM AT CONTRIBUTING TO TRANSFORM THE ADRIATIC AREA IN A STABLE HUB FOR A SUSTAINABLE TECHNOLOGICAL DEVELOPMENT[J]. International Journal for Quality Research, 2016, 10(1).

[9] York J G, Lenox M J. Exploring the sociocultural determinants of de novo versus de alio entry in emerging industries [J]. Strategic Management Journal, 2014, 35(13): 1930-1951.

[10] Weng H Y, Yang C H. Culture conservation and regeneration of traditional industries derived by tourism factory-Case study of Kwong xi paper factory in Taiwan [J]. International Journal of Humanities, Arts and Social Sciences, 2016, 2(5): 172-180. 